\title{
Neuropatia Periférica em Pacientes com Câncer Colorretal em Tratamento com Oxaliplatina
}

\author{
Oxaliplatin-Induced Peripheral Neuropathy In Patients With Colorectal Cancer \\ Helena Maria de Cerqueira Mathias ${ }^{1}$, Maria Cecilia Mathias Machado ${ }^{2}$, \\ Adriano Celso Rodrigues ${ }^{3}$
}

\section{RESUMO}

Introduçáo. A neuropatia periférica representa uma das principais queixas dos pacientes com câncer colorretal submetidos à quimioterapia com oxaliplatina, sendo necessária uma maior compreensão sobre o tema pela comunidade de saúde. Objetivo. Revisar a literatura referente à ocorrência de neuropatia periférica secundária à oxaliplatina em pacientes com câncer colorretal. Método. Pesquisa realizada nas bases de dados Medline e Science Direct, com período de coleta entre novembro de 2010 a fevereiro de 2011. Foram utilizados artigos científicos publicados nos últimos seis anos sobre o tema, sendo excluídos artigos de revisão de literatura e estudos experimentais em laboratório. Resultados. Após a pesquisa, foram selecionados 29 artigos para compor esse estudo, todos no idioma inglês. Nos artigos selecionados, observou-se que as principais manifestaçôes clínicas descritas foram parestesia distal, disestesia perioral e laringofaríngea, incapacidade funcional, diminuição ou ausência de reflexos tendíneos, hipersensibilidade ao frio, dor e contração muscular. Conclusóes. A frequência de neuropatia periférica em pacientes com câncer colorretal submetidos à quimioterapia com oxaliplatina é significativamente alta. Dessa forma, é essencial que os profissionais de saúde estejam atentos aos possíveis efeitos adversos dessa droga. Recomendam-se novos estudos com a finalidade de facilitar a busca de estratégias de prevençáo e tratamento para o mesmo.

Unitermos. Neoplasias Colorretais, Quimioterapia, Síndromes Neurotóxicas, Compostos de Platina, Polineuropatias, Polineuropatia Paraneoplásica.

Citaçáo. Mathias HMC, Machado MCM, Rodrigues AC. Neuropatia Periférica em Pacientes com Câncer Colorretal em Tratamento com Oxaliplatina.

\begin{abstract}
Introduction. Oxaliplatin-induced peripheral neuropathy is one of the main complaints of patients in treatment for colorectal cancer, therefore a better understanding of the subject is necessary in order to guide health professionals. Objective. Generalize the knowledge on oxaliplatin-induced peripheral neuropathy in patients with colorectal cancer. Method. This study consists of a literature review carried through consultation to the databases Medline and Science Direct, with data collection between November 2010 and February 2011. For this study, scientific articles published in the last six years were used, which adressed the subject. Literature review articles and laboratory experimental studies were excluded. Results. Upon research, 29 articles have been enclosed in this study, all of them in the English language. In these selected articles, the most frequent clinical effects were distal paresthesia, perioral and laryngopharingeal dysesthesia, functional impairment, loss or decrease of tendon reflexes, hypersensibility to cold, pain and muscle contraction. Conclusions. The frequency of oxaliplatin-induced peripheral neuropathy in patients with colorectal cancer is very high. Therefore, it is essential that health professionals be familiar to the adverse effects of this medication. New studies are recommended to facilitate the search of prevention and treatment for such medication induced toxicity.
\end{abstract}

Keywords. Colorectal Neoplasms, Drug Therapy, Neurotoxicity Syndromes, Platinum Compounds, Polineuropathies, Paraneoplastic Polyneuropathy.

Citation. Mathias HMC, Machado MCM, Rodrigues AC. Oxaliplatin-Induced Peripheral Neuropathy In Patients With Colorectal Cancer.
Trabalho realizado na Universidade Salvador (UNIFACS), Salvador-BA, Brasil.

1.Fisioterapeuta, Pós-graduanda da Universidade Salvador (UNIFACS), Salvador-BA, Brasil.

2.Acadêmica de Medicina, Escola Bahiana de Medicina e Saúde Pública (EBMSP), Salvador-BA, Brasil.

3.Fisioterapeuta, Especialista em Fisioterapia Traumatortopédica pela Universidade Gama Filho, Salvador-BA, Brasil.
Endereço para correspondência: Adriano Celso Rodrigues

Universidade Católica do Salvador Av. Anita Garibaldi Edf. Centro Odonto-médico Itamaraty, 8 andar, Ondina, Salvador-BA, Brasil Tel.: (71)8226-1504

E-mail: adriano.celso@uol.com.br 


\section{INTRODUÇÃO}

A Neuropatia Periférica induzida pela quimioterapia é um dos efeitos colaterais mais comuns e indesejáveis no tratamento do câncer colorretal ${ }^{1,2}$, e constitui um fator limitante para o uso de drogas potencialmente eficazes, sendo, muitas vezes, necessária a redução da dose ou a interrupção do tratamento ${ }^{3-5}$. A prevalência de neuropatia periférica relacionada ao uso de agentes quimioterápicos vem aumentando devido ao avanço na terapia adjuvante pós-operatória, que proporcionou uma maior sobrevida para os pacientes com esta patologia ${ }^{1,2}$. Recentemente, a adição de oxaliplatina aos regimes já utilizados como primeira linha de tratamento tem se destacado, tanto pela sua eficácia, quanto pela neurotoxicidade que acarreta, e apresenta, como uma das principais complicaçóes, a neuropatia periférica aguda ou crônica ${ }^{2,3,6-9}$.

Diferentes autores demonstraram a ocorrência de neuropatia periférica sensitiva associada ao uso da oxaliplatina $^{1-6,10}$. Essa neuropatia é caracterizada por disestesia, hipoestesia e/ou parestesia distal, e esses sintomas estão correlacionados com a dose administrada, aumentando de intensidade e duração conforme o efeito cumulativo da droga $a^{1-5,7,10}$. A neuropatia sensitiva é reversível, e responde a reduções de dose ou interrupção do tratamento, porém ela pode persistir durante meses, e, nestes casos, pode afetar a capacidade funcional do paciente e a habilidade de realizar suas atividades de vida diária ${ }^{1,3,4,11}$.

Os pacientes submetidos a esquemas de quimioterapia contendo oxaliplatina também podem apresentar manifestaçôes neurológicas agudas ${ }^{1,4-8,9,12}$. Estas iniciam durante a infusão, dentro de minutos ou horas, ou mesmo um a dois dias após a administração, apresentando resolução espontânea em poucos dias ${ }^{1,3,6,9,10,13}$. Os sinais e sintomas podem incluir disestesia, hipoestesia e parestesia induzidas pelo frio, os quais geralmente acometem mãos e pés, mas podem ocorrer também ao redor da boca e laringofaringe $e^{4}$. Outras disfunçôes sensitivas e motoras também são relatadas, tais como diplopia, rigidez mandibular, cãibra ou espasmo muscular, fraqueza generalizada, neuromiotonia e outros sinais de hiperexcitabilidade de nervos periféricos ${ }^{1,4,5,8-10}$.

Este quadro de desconforto representa uma das principais queixas dos pacientes em acompanhamento para neoplasia colorretal na clínica oncológica, interfe- rindo em suas atividades de vida diária, com consequente perda de qualidade de vida. Desta forma, uma maior compreensão sobre o tema é necessária para orientar a comunidade de saúde na busca de estratégias de tratamento para este agravo. Sendo assim, este trabalho tem como objetivo revisar a literatura referente à ocorrência de neuropatia periférica secundária à oxaliplatina em pacientes com câncer colorretal.

\section{MÉTODO}

Foi realizada uma revisão de literatura por meio do levantamento de publicaçôes que abordavam a neuropatia periférica em pacientes com câncer de cólon e reto submetidos à quimioterapia, com divulgaçôes em língua inglesa e portuguesa. As bases de dados utilizadas foram Medline e Science Direct e biblioteca virtual Bireme. A coleta de dados foi realizada entre janeiro de 2010 a fevereiro de 2011. Os artigos foram identificados através dos descritores: neoplasias colorretais, quimioterapia, síndromes neurotóxicas, polineuropatias, polineuropatia paraneoplásica, compostos de platina e seus correlatos em língua inglesa.

Foram incluídos estudos que relatavam a ocorrência de neuropatia periférica em pacientes portadores de câncer colorretal, submetidos ao tratamento quimioterápico com regimes baseados em oxaliplatina, publicados nos últimos seis anos, com data de divulgação entre 2006 a 2011. Pela relevância para a pesquisa, foram aceitas quatro publicações de anos anteriores a este período. Como critérios de exclusão, não foram aceitos artigos que tinham, como desenho de estudo, revisão de literatura e estudos experimentais em laboratório.

\section{RESULTADOS}

A pesquisa inicial realizada nas bases eletrônicas identificou 105 referências. Através da Medline, foram identificados 66 artigos e, pela Science Direct, foram localizados 41 artigos. Contudo, foram excluídos aqueles que não se adequavam ao objetivo da pesquisa, sendo selecionados 60 artigos para leitura de resumo. Dentre estes, foram ainda excluídos os que tinham como desenho de estudo revisão de literatura e aqueles que não preenchiam os critérios de inclusão previamente determinados. Foram, então, selecionados 29 artigos para compor esse 
estudo, todos no idioma inglês. Dos estudos incluídos, 25 foram publicados nos últimos seis anos e quatro tinham data de divulgação entre 2000 e 2005 . Esses foram constituídos, em sua maior parte, por ensaios clínicos, totalizando vinte e cinco artigos, dois estudos de coorte e dois estudos retrospectivos. Todas essas publicaçóes foram lidas na íntegra e preencheram os critérios propostos inicialmente (Tabela 1).

Nos artigos selecionados, observou-se que as principais manifestaçóes clínicas foram descritas e, entre estas, $85.7 \%$ descreveram parestesia distal, $85.7 \%$ relataram disestesia distal, perioral e laringofaríngea,71.4\% descreveram incapacidade funcional, $57.1 \%$ relataram diminuição ou ausência de reflexos tendíneos, 53.5\% descreveram hipersensibilidade ao frio, 50\% relataram dor e $42.8 \%$ descreveram contração muscular nas extremidades distais e região perioral. Embora menos frequentes, outros sintomas foram citados nos artigos, sendo que $21.4 \%$ relataram diminuição ou ausência de percepção vibratória, $21.4 \%$ descreveram ataxia sensorial e $17.8 \%$ relataram fraqueza muscular (Tabela 2).

\section{DISCUSSÃO}

As evidências científicas acerca das manifestaçóes clínicas da neuropatia periférica em pacientes com câncer colorretal submetidos à quimioterapia com oxaliplatina sugerem alta frequência de alteraçóes da sensibilidade e, também, está relacionada ao frio, presença de dor, contraçóes musculares, diminuição ou ausência de reflexos tendíneos e incapacidade funcional. Foi possível também observar, nos resultados de alguns estudos selecionados, que diminuição da percepção vibratória, fraqueza muscular e ataxia sensorial podem ocorrer e, desta forma, comprometer a qualidade de vida dos pacientes.

No presente estudo foi possível encontrar uma alta frequência de alteraçóes da sensibilidade, destacando-se a presença de parestesias e disestesias. Em um estudo ${ }^{1}$ com 86 adultos portadores de câncer colorretal submetidos à quimioterapia com oxaliplatina, a parestesia foi encontrada em 94,3\% dos pacientes durante a terapia, e este sintoma acometia principalmente os pés e as mãos. Os autores demonstraram que, após seis ciclos de tratamento, 92\% dos pacientes ainda apresentavam dormência e formigamento, e relacionaram este achado ao desenvolvimento de neuropatia crônica decorrente do efeito cumulativo da droga. A incidência desta complicação foi muito semelhante em outros estudos ${ }^{14,15}$. Em um deles ${ }^{14}$, foi relatada a ocorrência deste sintoma em 96\% dos indivíduos, enquanto, em outra pesquisa ${ }^{15}$, dos 27 pacientes estudados, 16 apresentaram quadro de parestesia em membros superiores e inferiores. Em discordância com esses achados, no protocolo NSABP C- $07^{2}$, os autores analisaram a neurotoxicidade secundária ao uso desta droga e não encontraram uma prevalência tão elevada desse sintoma, pois apenas 19,5\% dos pacientes apresentaram adormecimento ou formigamento em pés e mãos, porém enfatizaram a persistência dos sintomas, já que, 18 meses após o início do tratamento, $13.9 \%$ destes indivíduos ainda apresentavam parestesia nos pés.

Alteraçóes de sensibilidade secundária à quimioterapia com oxaliplatina foram descritas em um estudo ${ }^{16}$ com 135 pacientes com câncer de cólon e reto, que relatava a ocorrência de disestesia distal em 68 indivíduos, sendo que 9 deles apresentavam ainda disestesia e/ou parestesia na região oral e perioral e 7 evoluíram também com disestesia laringofaríngea. Outras pesquisas ${ }^{8,17}$ citaram também a presença desses sintomas na face e na faringe. Em uma delas ${ }^{17}$, foi observado que, dos 18 pacientes tratados com a referida droga, 13 apresentaram disestesia distal, perioral e laringofaríngea. Em outra pesquisa $^{8}$, da mesma forma, foi observada a presença de disestesia em faringe, relatada pelos pacientes como desconforto respiratório. A maioria dos autores concorda que a fisiopatologia desses sintomas sensitivos ainda não está completamente esclarecida, mas, provavelmente, esses se devem aos efeitos neurotóxicos do acúmulo da oxaliplatina nas células dos gânglios sensitivos dorsais, o que provoca mudanças morfológicas no corpo celular, e pode resultar em axonopatia dos nervos periféricos, especialmente nas fibras largas mielinizadas, responsáveis pela condução nervosa sensorial ${ }^{4,18,19}$.

Diversos autores observaram a relação desses sintomas sensitivos com o frio ${ }^{1,5,8,10,17,20,21}$. Em ensaio clíni$\mathrm{Co}^{20}$, com 48 adultos portadores de câncer colorretal, os autores relataram a ocorrência de parestesia e disestesia nas mãos desencadeada pelo frio em $96 \%$ dos pacientes, e disestesia na laringofaringe em 32\% desses. Em outra pesquisa $^{1}$, foi observado que $87.2 \%$ dos pacientes apre- 
sentavam disestesia na face e nas extremidades, e esta se manifestava como sensibilidade dolorosa ao frio quando os pacientes comiam, bebiam ou seguravam objetos frios. Em análise da duração desse sintoma, os autores perceberam que, após 6 ciclos de tratamento, apenas $68 \%$ dos indivíduos se queixavam deste acometimento, e sugeriram que estes sintomas estão geralmente associados ao fenômeno de hiperexcitabilidade transitória dos nervos periféricos. Achados semelhantes foram encontrados em outros estudos ${ }^{5,8,10,17,21}$, sendo que, em dois deles ${ }^{5,8}$ todos os pacientes submetidos ao tratamento relataram presença de parestesia induzida pelo frio após a infusão, com duração de três a vinte e um dias, enquanto, nas outras pesquisas ${ }^{10,17}$, os autores citaram a ocorrência de disetesia relacionada ao frio em $72 \%$ a $75 \%$ dos pacientes, os quais persistiram por dois a cinco dias após a infusão. Esses sintomas, desencadeados ou aumentados pela exposição à temperatura fria, estâo relacionados à neuropatia aguda, e, geralmente, são suaves, de curta duraçáo, e completamente reversíveis dentro de horas ou dias ${ }^{4,18}$. Até o momento, a hipótese mais aceita sugere que estes efeitos agudos se devem à combinação do cálcio com o oxalato liberado pela oxaliplatina na membrana sináptica, provocando alteraçôes nos canais de sódio voltagem-dependentes, com consequente aumento da excitabilidade das células nervosas e musculares ${ }^{4,18,22,23}$.

No atual estudo, foi encontrada, também, uma alta incidência de dor, principalmente, relacionada ao frio. Autores ${ }^{24}$ avaliaram 16 pacientes com câncer tratados com oxaliplatina através do questionário McGill, específico pra dor, e observaram que, dentre estes, 9 apresentaram queixa de dor, e todos relataram associação desta com o frio, provocada pelo ambiente com baixas temperaturas e/ou contato com objetos, líquidos ou ar frio. Em uma pesquisa ${ }^{20}$, foi descrita, além das alteraçóes de sensibilidade já citadas, a ocorrência de dor nas mãos relacionada ao frio, após cada ciclo de tratamento, em $96 \%$ dos indivíduos estudados. Outros autores ${ }^{1}$ verificaram que a dor provocada pelo frio era o sintoma mais comum experimentado pelos pacientes durante o tratamento, acometendo mais de $80 \%$ destes. Outro estudo ${ }^{2}$ apresentou uma incidência bem mais baixa desse sintoma que a citada pelos outros autores, de apenas 26\%. Esse sintoma parece ocorrer pelo fato de que a neurotoxicidade da oxaliplatina é mediada pela sensibilização dos sistemas nociceptivos periféricos e centrais ${ }^{24}$. Essa droga também exerce efeito significativo no potencial de ação das fibras mielinizadas tipo A Delta, responsáveis pela condução do estímulo térmico relacionado ao frio ${ }^{20,24}$.

Além da dor induzida pelo frio, em estudo já referido $^{1}$, os autores observaram que $60 \%$ dos pacientes queixavam-se de dor ao morder os alimentos, devido ao espasmo da musculatura mastigatória. Contraçôes musculares, como espasmos, rigidez e cãibras musculares foram citados em várias pesquisas ${ }^{5,21,25,26}$. Em dois estu$\mathrm{dos}^{5,25}$, realizados pelo mesmo grupo de pesquisadores, foi demonstrado, através de avaliação neurológica, que, após infusão da oxaliplatina, sete, entre os dez pacientes examinados, mantinham a contração muscular dos extensores das mãos após percussão do nervo interósseo por tempo mais prolongado do que em indivíduos normais. Em pesquisa ${ }^{26}$ recente conduzida com 15 pacientes com câncer avaliados antes e após infusão da oxaliplatina, foi observado que $13 \%$ destes evoluíram com cãibras e fasciculaçóes em mãos e pés com duração de 2 a 10 dias após aplicação da droga, enquanto $7 \%$ dos indivíduos apresentaram dor e rigidez mandibular. Esses sintomas apresentam semelhança clínica com espasmos tetânicos, os quais são geralmente atribuídos à hiperexcitabilidade dos neurônios motores e associados à hipocalcemia e hipomagnesemia ${ }^{4}$.

Outro sintoma diversamente citado no presente estudo foi a diminuição ou ausência de reflexos tendíneos. Em análise da neurotoxicidade secundária ao uso da oxaliplatina, autores ${ }^{20}$ realizaram exame neurológico em 18 pacientes do grupo que recebeu esta droga 12,2 meses após o término da quimioterapia. Deste total, 12 indivíduos ainda apresentavam evidência clínica de neuropatia periférica em membros superiores e/ou inferiores, com diminuição ou ausência de reflexos tendíneos em $50 \%$ deles. Outros estudos ${ }^{9,17,27}$ também relacionaram este sintoma à neurotoxicidade crônica associada a essa droga. Em um deles ${ }^{17}$, os pesquisadores estudaram dois grupos de pacientes com câncer colorretal avançado em tratamento com oxaliplatina, sendo que o primeiro foi avaliado no momento da infusão, 9 e 18 semanas após início da quimioterapia; enquanto o segundo grupo foi examinado dias após o término da terapia e acompanhado 
durante 7 meses. Os autores relataram que 55\% dos pacientes apresentaram hiporreflexia dos tendóes profundos após 9 semanas, 45\% evoluíram com este sintoma após 18 semanas, e $76 \%$ dos indivíduos ainda apresentavam esse acometimento após 7 meses de seguimento. Outra pesquisa $^{13}$ associou o grau da neuropatia com este sintoma e observou que, dos 25 adultos com câncer de cólon metastático estudados, 6 indivíduos com neuropatia leve mantiveram o reflexo do tornozelo preservado, enquanto 8 pacientes com neurotoxicidade moderada apresentaram hiporreflexia, e 2 indivíduos com toxicidade elevada cursaram com arreflexia e hiporreflexia do tornozelo. Esses sintomas ocorrem quando há comprometimento dos elementos que constituem o arco reflexo, nesse caso, provavelmente, deve-se ao acúmulo de oxaliplatina nas células dos gânglios sensitivos dorsais, atingindo as fibras grossas mielinizadas que compóem este sistema ${ }^{4,18,19,28,29}$.

Diversos autores analisaram a gravidade e a duração da neuropatia associada ao tratamento com oxaliplatina $^{2,6,9,30}$. Para esta finalidade, os instrumentos mais utilizados foram a escala de neurotoxicidade do Instituto Nacional do Câncer e uma escala desenvolvida especificamente para avaliar a neurotoxicidade secundária a essa droga. Esta última possui um sistema de graduação, no qual pacientes com grau 1 apresentam parestesia e disestesia de curta duração; grau 2 são aqueles que cursam com parestesia e disestesia persistindo entre os ciclos de tratamento e grau 3 quando esses sintomas evoluem para incapacidade funcional ${ }^{4,18}$.

Em estudo europeu ${ }^{30}$ realizado com pacientes com câncer colorretal, 18\% dos indivíduos do grupo que utilizou oxaliplatina apresentaram toxicidade neurosensitiva de grau 3 em algum período do tratamento. Valores semelhantes foram encontrados em outras pesquisas ${ }^{6,9}$. No estudo MOSAIC ${ }^{6}$, no qual 2246 pacientes com câncer de cólon estágio II e III foram avaliados entre outubro de 1998 a janeiro de 2001 e acompanhados nos seis anos subsequentes, os autores relataram que $12.5 \%$ dos pacientes tratados com oxaliplatina desenvolveram parestesia de grau 3 durante o tratamento. As taxas de toxicidade de grau 3 nesses estudos são mais altas do que os $8,4 \%$ detectados no protocolo NSABP C- $07^{2}$, em parte, devido à inclusão de 2 semanas de descanso no esquema de qui- mioterapia. Além disso, o tratamento teve duração mais longa para muitos pacientes com doença avançada.

Resultados sobre a reversibilidade da neurotoxicidade têm sido contraditórios. No estudo europeu ${ }^{30}$, com seguimento mediano de 27,7 meses, a toxicidade neurosensitiva de grau 3 foi reversível em $74 \%$ dos pacientes ${ }^{3}$. Por outro lado, $0,7 \%$ dos pacientes no grupo que fazia uso de oxaliplatina no estudo MOSAIC ${ }^{6}$ apresentavam toxicidade neurossensitiva de grau 3 aos 18 meses. No entanto, tanto o estudo MOSAIC quanto o estudo do NSABP C-07 mostraram que a neurotoxicidade de menor grau continuou em boa parcela dos pacientes durante o seguimento ${ }^{2,6}$. Os estudos mostram que quase $25 \%$ dos pacientes participantes do estudo MOSAIC e 40\% dos pacientes do NSABP C-07 ainda apresentavam sintomatologia neuropática após 1 ano de acompanhamento ${ }^{2,6}$. Até que ponto a neurotoxicidade influencia na qualidade de vida ainda não está claro, em virtude das conclusóes inconsistentes de alguns estudos ${ }^{2,6,9}$. Porém, pacientes que evoluem com incapacidade funcional relatam dificuldade na realização de atividades de vida diária relacionadas à coordenação motora fina, como abotoar camisas, escrever ou segurar objetos ${ }^{17,18,31,32}$.

Embora menos citado nos artigos selecionados, talvez pela não aplicação de exames neurológicos específicos, a diminuição ou ausência de percepção vibratória foi um dos resultados encontrados no presente estudo. Em pesquisa ${ }^{17}$ referida anteriormente, os autores observaram que, dos 18 pacientes submetidos à quimioterapia com oxaliplatina, 38\% apresentaram hipopalestesia 9 semanas após o início do tratamento, e todos evoluíram com esse sintoma 18 meses após a primeira infusão. Esses autores relataram também que $76 \%$ dos indivíduos ainda apresentavam diminuição de percepção vibratória após 7 meses de acompanhamento, sem sinais de melhora clínica. Outros estudos ${ }^{9,13,27}$ descreveram diminuição da sensibilidade vibratória distal nesses pacientes, sendo que dois deles ${ }^{9,13}$ relataram a ocorrência desse sintoma em membros superiores e membros inferiores, enquanto outro ${ }^{27}$ encontrou apenas em membros inferiores. Esse acometimento, provavelmente, deve-se à ação tóxica da oxaliplatina nos neurônios sensoriais, atingindo as fibras grossas mielinizadas responsáveis pela condução da sensação vibratória. 
Tabela 1

Características metodológicas dos estudos que relataram as manifestaçöes clínicas da neuropatia periférica em pacientes com câncer colorretal submetidos à quimioterapia com oxaliplatina

\begin{tabular}{|c|c|c|c|c|c|c|}
\hline $\begin{array}{c}\text { Autores e } \\
\text { Ano de } \\
\text { publicaçáo }\end{array}$ & $\begin{array}{c}\text { Delineamento } \\
\text { do estudo }\end{array}$ & Amostra & Instrumentos & Resultados & Discussão & Comentários \\
\hline $\begin{array}{l}\text { Leonard et } \\
\text { al. }^{1} \\
2005\end{array}$ & $\begin{array}{l}\text { Ensaio clínico } \\
\text { fase I }\end{array}$ & $\begin{array}{l}86 \text { pacientes com } \\
\text { idade entre } 26 \text { e } 74 \\
\text { anos ( } 56 \text { homens e } \\
30 \text { mulheres), com } \\
\text { câncer de cólon, reto } \\
\text { ou apêndice. }\end{array}$ & $\begin{array}{l}\text { Questionário/Sistema } \\
\text { de graduação da } \\
\text { neurotoxicidade }\end{array}$ & $\begin{array}{l}87.2 \% \text { dos pacientes } \\
\text { experimentaram dise- } \\
\text { tesia na face e extre- } \\
\text { midades, } 94.3 \% \text { deles } \\
\text { experimentaram pa- } \\
\text { restesia nas mãos e pés } \\
\text { em algum momento } \\
\text { da quimioterapia com } \\
\text { oxaliplatina. Alguns } \\
\text { pacientes evoluíram } \\
\text { com incapacidade } \\
\text { funcional com uso de } \\
\text { doses mais elevadas. }\end{array}$ & $\begin{array}{l}\text { Os resultados demons- } \\
\text { traram que a maioria } \\
\text { dos pacientes apresentou } \\
\text { neurotoxicidade leve a } \\
\text { moderada. Porém, os } \\
\text { autores enfatizaram a } \\
\text { possibilidade da ocorrên- } \\
\text { cia de neuropatia severa } \\
\text { com uso de doses mais } \\
\text { elevadas, o que pode } \\
\text { interferir na qualidade de } \\
\text { vida destes pacientes. }\end{array}$ & $\begin{array}{l}\text { Bom estudo. Descreveu } \\
\text { com detalhes a intensi- } \\
\text { dade, tipo, localização e } \\
\text { duração da neuropatia } \\
\text { periférica associada } \\
\text { à quimioterapia com } \\
\text { oxaliplatina. }\end{array}$ \\
\hline $\begin{array}{l}\text { Land et al. }{ }^{2} \\
2007\end{array}$ & $\begin{array}{l}\text { Ensaio clínico, } \\
\text { multicêntrico, } \\
\text { randomizado, } \\
\text { fase III }\end{array}$ & $\begin{array}{l}2492 \text { pacientes, com } \\
\text { idade entre } 17 \text { e } 85 \\
\text { anos, } 1391 \text { homens } \\
\text { e } 1074 \text { mulheres, } \\
\text { com câncer de colon } \\
\text { está-gio II e III. } \\
\text { Subestudo com } 400 \\
\text { pacientes. }\end{array}$ & $\begin{array}{l}\text { Functional Asses- } \\
\text { sment of Cancer } \\
\text { Therapy/ Gynecologic } \\
\text { Oncology Group } \\
\text { OxaliplatinNeuro- } \\
\text { toxicity/NCI-Sanofi } \\
\text { Criteria }\end{array}$ & $\begin{array}{l}\text { Dormência e formi- } \\
\text { gamento em mãos e } \\
\text { pés, desconforto nas } \\
\text { mãos, dor em mãos e } \\
\text { pés induzida pelo frio e } \\
\text { fraqueza geral. Nos } 18 \\
\text { meses de seguimento, } \\
\text { a neurotoxicidadese } \\
\text { mostrou-se mais severa } \\
\text { no grupo que recebeu } \\
\text { oxaliplatina, atingin-do } \\
\text { principalmente os pés. }\end{array}$ & $\begin{array}{l}\text { Os autores demonstraram } \\
\text { que o grupo que recebeu } \\
\text { oxaliplatina apresentou } \\
\text { maior neurotoxicidade } \\
\text { em todas as etapas do } \\
\text { tratamento, além de } \\
\text { maior persistência e } \\
\text { severidade da neuropatia } \\
\text { no seguimento realizado } \\
\text { aos } 6 \text { e } 18 \text { meses após o } \\
\text { término da terapia. }\end{array}$ & $\begin{array}{l}\text { Bom estudo randomi- } \\
\text { zado. Descreve detalha- } \\
\text { damente aspectos sobre } \\
\text { a neuropatia periférica } \\
\text { secundária ao uso de } \\
\text { oxaliplatina. }\end{array}$ \\
\hline $\begin{array}{l}\text { Wang et } \\
\text { al. }^{3} \\
2007\end{array}$ & $\begin{array}{l}\text { Ensaio clínico } \\
\text { randomizado }\end{array}$ & $\begin{array}{l}86 \text { pacientes adultos } \\
\text { ( } 56 \text { homens e } 30 \\
\text { mulheres), com } \\
\text { câncer de cólon e } \\
\text { reto, randomizados } \\
\text { em dois grupos } \\
\text { para receber ou não } \\
\text { glutamina. }\end{array}$ & $\begin{array}{l}\text { National Cancer } \\
\text { Institute Common } \\
\text { Toxicity Criteria } \\
\text { (NCI-CTC) }\end{array}$ & $\begin{array}{l}\text { Pacientes experimen- } \\
\text { taram parestesia e } \\
\text { disestesia em mãos e } \\
\text { pés assim como laringe } \\
\text { e mandíbula. }\end{array}$ & $\begin{array}{l}\text { Os autores sugeriram } \\
\text { que a glutamina tem } \\
\text { funçấo neuroprotetora } \\
\text { na neuropatia periférica } \\
\text { secundária à oxaliplatina } \\
\text { em pacientes com câncer } \\
\text { de cólon e reto. }\end{array}$ & $\begin{array}{l}\text { Não apresenta detalhes } \\
\text { sobre sintomas, tipo e } \\
\text { localização da neuro- } \\
\text { patia periférica secun- } \\
\text { dária à oxaliplatina. } \\
\text { Tamanho da amostra } \\
\text { reduzido. }\end{array}$ \\
\hline $\begin{array}{l}\text { Wilson et } \\
\text { al. }^{5} \\
2002\end{array}$ & $\begin{array}{l}\text { Ensaio clínico } \\
\text { fase I }\end{array}$ & $\begin{array}{l}\text { Subestudo com } 13 \\
\text { pacientes }\end{array}$ & $\begin{array}{l}\text { Eletroneuromiografia } \\
\text { e questionário } \\
\text { para avaliação dos } \\
\text { sintomas. }\end{array}$ & $\begin{array}{l}\text { Todos os pacientes } \\
\text { experimentaram } \\
\text { neurotoxicidade aguda } \\
\text { secundária a oxalipla- } \\
\text { tina, com parestesia e } \\
\text { disestesia nas mãos, pés } \\
\text { e regiāo perioral, dises- } \\
\text { tesia faringolaringeal } \\
\text { e hipersensibilidade } \\
\text { ao frio. }\end{array}$ & $\begin{array}{l}\text { Os autores sugeriram } \\
\text { que a neuropatia aguda } \\
\text { secundária a oxaliplatina } \\
\text { caracteriza-se pela hipere- } \\
\text { xcitabilidade do nervo pe- } \\
\text { riférico, assemelhando-se } \\
\text { às manifestaçóes clínicas } \\
\text { da neuromiotonia. }\end{array}$ & $\begin{array}{l}\text { Tamanho da amostra } \\
\text { muito reduzido. }\end{array}$ \\
\hline $\begin{array}{l}\text { Thierry et } \\
\text { al. }^{6} \\
2009\end{array}$ & $\begin{array}{l}\text { Ensaio clínico, } \\
\text { multicêntrico, } \\
\text { randomizado }\end{array}$ & $\begin{array}{l}2246 \text { pacientes, com } \\
\text { idade entre } 18 \text { e } 75 \\
\text { anos, que realizaram } \\
\text { ressecção completa } \\
\text { de câncer de cólon } \\
\text { estágio II ou III. }\end{array}$ & $\begin{array}{l}\text { National Cancer } \\
\text { Institute Common } \\
\text { Toxicity Criteria, } \\
\text { versão } 1\end{array}$ & $\begin{array}{l}\text { Parestesia distal } \\
\text { durante a terapia com } \\
\text { oxaliplatina. Neuro- } \\
\text { patia periférica grau } 3 \\
\text { ocorreu em } 12.5 \% \text { dos } \\
\text { pacientes, interfe- } \\
\text { rindo com a função. } \\
\text { Depois de } 18 \text { meses, } \\
24,1 \% \text { dos pacientes } \\
\text { ainda apresentavam } \\
\text { sintomas, sendo que } \\
0.7 \% \text { com incapacida- } \\
\text { de funcional. } 48 \text { meses } \\
\text { depois sintomas ainda } \\
\text { presentes. }\end{array}$ & $\begin{array}{l}\text { Os resultados sugeriram } \\
\text { que a terapia adjuvante } \\
\text { de oxalipaltina com FU e } \\
\text { leucovorin deve ser utili- } \\
\text { zada depois da cirurgia de } \\
\text { pacientes com câncer de } \\
\text { cólon estágio II. O efeito } \\
\text { adverso mais preocupante } \\
\text { é a neuropatia periférica } \\
\text { decorrente da terapia. }\end{array}$ & $\begin{array}{l}\text { Bom estudo rando- } \\
\text { mizado, mas não foca } \\
\text { nos detalhes sobre a } \\
\text { neuropatia periférica } \\
\text { relacionada à quimiote- } \\
\text { rapia com oxaliplatina. }\end{array}$ \\
\hline
\end{tabular}


Tabela 1

(continuação)

\begin{tabular}{|c|c|c|c|c|c|c|}
\hline $\begin{array}{c}\text { Autores e } \\
\text { Ano de } \\
\text { publicaçáo }\end{array}$ & $\begin{array}{c}\text { Delineamento } \\
\text { do estudo }\end{array}$ & Amostra & Instrumentos & Resultados & Discussáo & Comentários \\
\hline $\begin{array}{l}\text { Hill et al. } \\
2010\end{array}$ & $\begin{array}{l}\text { Ensaio clínico } \\
\text { prospectivo }\end{array}$ & $\begin{array}{l}29 \text { pacientes adultos } \\
\text { ( } 22 \text { homens e } 7 \\
\text { mulheres) com idade } \\
\text { entre } 28 \text { e } 79 \text { anos, } \\
\text { com diagnóstico de } \\
\text { câncer colorretal } \\
\text { metastático, câncer } \\
\text { de cabeça e pescoço } \\
\text { e câncer de pulmão. }\end{array}$ & $\begin{array}{l}\text { Eletroneuromiografia } \\
\text { e questionário } \\
\text { para avaliaçáo dos } \\
\text { sintomas. }\end{array}$ & $\begin{array}{l}\text { Parestesia induzida } \\
\text { pelo frio em } 100 \% \text { dos } \\
\text { pacientes, sensação de } \\
\text { aperto na mandíbula } \\
\text { ou garganta em } 68 \% \\
\text { deles, dor no membro } \\
\text { superior no local da } \\
\text { infusão em } 55 \% \text { dos } \\
\text { pacientes. Foram tam- } \\
\text { bém relatadas cáibras } \\
\text { musculares e dificulda- } \\
\text { de para respirar. }\end{array}$ & $\begin{array}{l}\text { Os autores sugeriram } \\
\text { que as características } \\
\text { neurofisiológicas da hipe- } \\
\text { rexcitabilidade neuromo- } \\
\text { tora aguda relacionada à } \\
\text { oxaliplatina é semelhante } \\
\text { à neuromiotonia. }\end{array}$ & $\begin{array}{l}\text { Bom estudo, porém } \\
\text { tamanho da amostra } \\
\text { reduzido. }\end{array}$ \\
\hline $\begin{array}{l}\text { Park et al. }{ }^{9} \\
2009\end{array}$ & Coorte & $\begin{array}{l}58 \text { pacientes, com } \\
\text { idade entre } 22 \text { e } 77 \\
\text { anos, com câncer } \\
\text { colorretal estágio III } \\
\text { ou IV tratados com } \\
\text { regimes baseados em } \\
\text { oxaliplatina. }\end{array}$ & $\begin{array}{l}\text { National Cancer } \\
\text { Institute Common } \\
\text { Toxicity Criteria } \\
\text { (NCI-CTC), versão } 3 \\
\text { /Oxaliplatin-Specific } \\
\text { Neurotoxicity Scale }\end{array}$ & $\begin{array}{l}94 \% \text { dos pacien- } \\
\text { tes apresentaram } \\
\text { neurotoxicidade } \\
\text { aguda relacionada à } \\
\text { oxaliplatina. } 20 \% \text { deles } \\
\text { experimentaram neu- } \\
\text { ropatia crônica severa. } \\
\text { Sintomas relatados: } \\
\text { parestesia distal, dor- } \\
\text { mência, diminuição da } \\
\text { sensibilidade vibratória } \\
\text { nas extremidades, au- } \\
\text { sência ou diminuiçấo } \\
\text { dos reflexos tendíneos } \\
\text { e ataxia nos casos mais } \\
\text { severos. }\end{array}$ & $\begin{array}{l}\text { Apesar da ligação entre } \\
\text { a neurotoxicidade aguda } \\
\text { e crônica induzida pela } \\
\text { oxaliplatina não estar bem } \\
\text { definida na literatura, os } \\
\text { autores sugeriram que a } \\
\text { modulação dos canais de } \\
\text { Na que ocorre durante } \\
\text { a fase aguda influencia a } \\
\text { severidade da neuro- } \\
\text {-toxicidade secundária a } \\
\text { esta droga. }\end{array}$ & $\begin{array}{l}\text { Tamanho da amostra } \\
\text { reduzido. }\end{array}$ \\
\hline $\begin{array}{l}\text { Petrioli et } \\
\text { al. }^{10} \\
2006\end{array}$ & $\begin{array}{l}\text { Ensaio clínico } \\
\text { prospectivo }\end{array}$ & $\begin{array}{l}33 \text { pacientes (19 } \\
\text { homens e } 14 \text { mu- } \\
\text { lheres), com idade } \\
\text { entre } 47 \text { e } 79 \text { anos, } \\
\text { com câncer color- } \\
\text { retal, tratados com } \\
\text { regimes baseados em } \\
\text { oxaliplatina. }\end{array}$ & $\begin{array}{l}\text { National Cancer } \\
\text { Institute Common } \\
\text { Toxicity Criteria } \\
\text { (NCI-CTC), versão } \\
\text { 2/ Oxaliplatin- } \\
\text { Specific Neurotoxicity } \\
\text { Scale/ Testes } \\
\text { para avaliaçáo } \\
\text { proprioceptiva e } \\
\text { exteroceptiva. }\end{array}$ & $\begin{array}{l}87.5 \% \text { dos pacientes } \\
\text { apresentaram neuropa- } \\
\text { tia periférica durante o } \\
\text { tratamento. } 75 \% \text { deles } \\
\text { relataram disestesia in- } \\
\text { duzida pelo frio. } 3.1 \% \\
\text { dos pacientes evoluí- } \\
\text { ram com incapacidade } \\
\text { funcional após onze } \\
\text { ciclos de tratamento. }\end{array}$ & $\begin{array}{l}\text { Os autores sugeriram que } \\
\text { o uso da estratégia "stop } \\
\text { and go" associado à qui- } \\
\text { mioterapia de manuten- } \\
\text { çâo com capecitabina está } \\
\text { relacionado a uma baixa } \\
\text { incidência de neuropatia } \\
\text { severa em pacientes trata- } \\
\text { dos com oxaliplatina. }\end{array}$ & $\begin{array}{l}\text { Tamanho da amostra } \\
\text { reduzido. Apesar de } \\
\text { utilizar escalas para ava- } \\
\text { liaçấo proprioceptiva e } \\
\text { exteroceptiva, não há } \\
\text { relato sobre os resulta- } \\
\text { dos desses exames. }\end{array}$ \\
\hline $\begin{array}{l}\text { Baek et } \\
\text { al. }{ }^{11} \\
2010\end{array}$ & $\begin{array}{l}\text { Ensaio clínico } \\
\text { prospectivo }\end{array}$ & $\begin{array}{l}366 \text { pacientes adul- } \\
\text { tos (201 homens e } \\
165 \text { mulheres), com } \\
\text { idade entre } 24 \text { e } 75 \\
\text { anos, com cancer de } \\
\text { cólon, tratados com } \\
\text { regimes quimioterá- } \\
\text { picos baseado sem } \\
\text { oxaliplatina. }\end{array}$ & $\begin{array}{l}\text { National } \\
\text { Cancer Institute } \\
\text { Common Toxicity } \\
\text { Criteria(NCI-CTC) } \\
\text { versão } 3\end{array}$ & $\begin{array}{l}\text { Pacientes experimenta- } \\
\text { ram parestesia e dises- } \\
\text { tesia nas extremidades. } \\
\text { Em alguns casos houve } \\
\text { comprometimento da } \\
\text { capacidade de realizar } \\
\text { suas atividades de vida } \\
\text { diária. }\end{array}$ & $\begin{array}{l}\text { Os autores náo conse- } \\
\text { guiram estabelecer os } \\
\text { parâmetros clínicos que } \\
\text { propiciam o desenvol- } \\
\text { vimento de neuropatia } \\
\text { severa em pacientes com } \\
\text { câncer de cólon tratados } \\
\text { com oxaliplatina. }\end{array}$ & $\begin{array}{l}\text { Poderia apresentar } \\
\text { mais detalhes sobre os } \\
\text { sintomas, tipo e loca- } \\
\text { lização da neuro-patia } \\
\text { periférica secundária à } \\
\text { oxaliplatina. }\end{array}$ \\
\hline $\begin{array}{l}\text { Kuebler et } \\
\text { al. }{ }^{12} \\
2007\end{array}$ & $\begin{array}{l}\text { Ensaio clínico, } \\
\text { randomizado, } \\
\text { multicêntrico, } \\
\text { prospectivo, } \\
\text { fase III. }\end{array}$ & $\begin{array}{l}2492 \text { pacientes, com } \\
\text { idade entre } 17 \text { e } 85 \\
\text { anos, (1391 homens } \\
\text { e } 1074 \text { mulheres), } \\
\text { com câncer de cólon } \\
\text { estágio II e III. }\end{array}$ & \begin{tabular}{|l|} 
National Cancer \\
Institute Common \\
Toxicity Criteria \\
(NCI-CTC) versão 2
\end{tabular} & $\begin{array}{l}\text { Pacientes apresentaram } \\
\text { dormência e formiga- } \\
\text { mento em mãos e pés, } \\
\text { desconforto nas mãos, } \\
\text { dor em mãos e pés in- } \\
\text { duzida pelo frio. } 8.4 \% \\
\text { deles evoluíram com } \\
\text { incapacidade funcional } \\
\text { com uso de doses mais } \\
\text { elevadas. }\end{array}$ & $\begin{array}{l}\text { Os autores demonstraram } \\
\text { que o grupo que recebeu } \\
\text { oxaliplatina apresentou } \\
\text { maior neurotoxicidade } \\
\text { em todas as etapas do } \\
\text { tratamento. }\end{array}$ & $\begin{array}{l}\text { Bom estudo rando- } \\
\text { mizado. Os autores } \\
\text { associam com clareza } \\
\text { os resultados com as } \\
\text { evidências já descritas } \\
\text { na literatura. }\end{array}$ \\
\hline
\end{tabular}


Tabela 1

(continuação)

\begin{tabular}{|c|c|c|c|c|c|c|}
\hline $\begin{array}{c}\text { Autores e } \\
\text { Ano de } \\
\text { publicaçáo }\end{array}$ & $\begin{array}{c}\text { Delineamento } \\
\text { do estudo }\end{array}$ & Amostra & Instrumentos & Resultados & Discussáo & Comentários \\
\hline $\begin{array}{l}\text { Argyriou et } \\
\text { al. }^{13} \\
2007\end{array}$ & Ensaio clínico & $\begin{array}{l}25 \text { pacientes acima } \\
\text { de } 18 \text { anos (17 ho- } \\
\text { mens e } 8 \text { mulheres), } \\
\text { com idade entre } 48 \\
\text { e } 78 \text { anos, com diag- } \\
\text { nóstico de câncer de } \\
\text { cólon metastático. }\end{array}$ & $\begin{array}{l}\text { Neurological } \\
\text { Sympton Score } \\
\text { (NSS), Neurological } \\
\text { Disability Score } \\
\text { (NDS), Functional } \\
\text { Grading scale (FGS) }\end{array}$ & $\begin{array}{l}\text { Evidências clínicas de } \\
\text { neuropatia periférica } \\
\text { em } 64 \% \text { dos pacientes. } \\
\text { Todos experimentaram } \\
\text { sintomas positivos, } \\
\text { como dormência e } \\
\text { dor, enquanto dois } \\
\text { apresentaram sintomas } \\
\text { negativos, como } \\
\text { marcha instável e difi- } \\
\text { culdade em identificar } \\
\text { objetos com as máos e } \\
\text { boca. Diminuiçấo da } \\
\text { sensação de vibração, } \\
\text { propriocepção e refle- } \\
\text { xos tendíneos foram } \\
\text { observados. }\end{array}$ & $\begin{array}{l}\text { A maioria dos pacientes } \\
\text { com câncer de cólon } \\
\text { tratados com o regime } \\
\text { FOLFOX-4 manifestaram } \\
\text { uma neuropatia periférica } \\
\text { predominantemente } \\
\text { sensorial distal, axonal, } \\
\text { simétrica, de severidade } \\
\text { suave a moderada. }\end{array}$ & $\begin{array}{l}\text { Avaliaçấo apenas da } \\
\text { neuropatia crônica, não } \\
\text { avalia neuropatia agu- } \\
\text { da. Não foram utiliza- } \\
\text { das as escalas aplicadas } \\
\text { em oncologia, o que } \\
\text { dificulta a comparação } \\
\text { com outros estudos. }\end{array}$ \\
\hline $\begin{array}{l}\text { Ishibashi et } \\
\text { al. }^{14} \\
2010\end{array}$ & $\begin{array}{l}\text { Ensaio clínico } \\
\text { randomizado, } \\
\text { prospectivo }\end{array}$ & $\begin{array}{l}33 \text { pacientes (16 } \\
\text { homens e } 17 \\
\text { mulheres), com } \\
\text { idade entre } 32 \text { e } 74 \\
\text { anos, com câncer } \\
\text { colorretal, tratados } \\
\text { com oxaliplatina, } \\
\text { randomizados em } \\
\text { dois grupos: pacien- } \\
\text { tes que receberam } \\
\text { ou náo } \mathrm{Ca} / \mathrm{Mg} \text {. }\end{array}$ & $\begin{array}{l}\text { National Cancer } \\
\text { Institute Common } \\
\text { Toxicity Criteria } \\
\text { (NCI-CTC) versão } 3 \\
\text { Neurotoxicity Criteria } \\
\text { of Debiopharm } \\
\text { (DEB-NTC) }\end{array}$ & $\begin{array}{l}100 \% \text { dos pacientes } \\
\text { apresentaram disestesia } \\
\text { e parestesia de curta } \\
\text { duração (aguda), em } \\
6 \% \text { deles os sintomas } \\
\text { persistiram entre os } \\
\text { ciclos de trata- mento, } \\
\text { e } 6 \% \text { apresentaram in- } \\
\text { capacidade funcional. }\end{array}$ & $\begin{array}{l}\text { Os autores não apresenta- } \\
\text { ram resultados conclusi- } \\
\text { vos sobre a neuroproteçáo } \\
\text { do Ca/Mg em pacientes } \\
\text { tratados com oxaliplatina. }\end{array}$ & $\begin{array}{l}\text { Tamanho da amostra } \\
\text { reduzido. Poderia } \\
\text { abordar outros aspectos } \\
\text { sobre a neuroropatia } \\
\text { periférica secundária } \\
\text { à oxaliplatina, como } \\
\text { duração, tipo e loca- } \\
\text { lização. }\end{array}$ \\
\hline $\begin{array}{l}\text { Chay et } \\
\text { al. } .^{15} \\
2010\end{array}$ & $\begin{array}{l}\text { Ensaio clínico } \\
\text { prospectivo, } \\
\text { randomizado } \\
\text { fase II }\end{array}$ & $\begin{array}{l}27 \text { pacientes (14 } \\
\text { homens e } 13 \text { mulhe- } \\
\text { res), com idade entre } \\
18 \text { e } 75 \text { anos, com } \\
\text { câncer colorretal, } \\
\text { tratados com qui- } \\
\text { mioterapia baseada } \\
\text { em oxaliplatina, } \\
\text { randomizados em } \\
\text { dois grupos: pacien- } \\
\text { tes que receberam } \\
\text { ou não infusőes de } \\
\mathrm{Ca} / \mathrm{Mg} \text {. }\end{array}$ & $\begin{array}{l}\text { National } \\
\text { CancerInstitute } \\
\text { Common Toxicity } \\
\text { Criteria (NCI-CTC), } \\
\text { versão 3/ Oxaliplatin- } \\
\text { Specific Neurotoxicity } \\
\text { Scale }\end{array}$ & $\begin{array}{l}\text { Do total de } 27 \text { pacien- } \\
\text { tes, } 22 \text { experimentaram } \\
\text { sintomas neuropáticos } \\
\text { agudos, como pareste- } \\
\text { sia e disestesia induzida } \\
\text { pelo frio. Com doses } \\
\text { mais elevadas, os } \\
\text { pacientes apresenta- } \\
\text { ram dormência que } \\
\text { persistiu entre os ciclos } \\
\text { de tratamento. } 11 \% \\
\text { deles experimentaram } \\
\text { neuropatia grau 3, } \\
\text { interferindo com a } \\
\text { funçấo. }\end{array}$ & $\begin{array}{l}\text { Os autores demonstraram } \\
\text { o efeito neuroprotetor } \\
\text { do Ca/Mg na neuro- } \\
\text { patia aguda, mas não } \\
\text { encontraram associação } \\
\text { do mesmo com a redução } \\
\text { dos sintomas neuropáti- } \\
\text { cos crônicos. }\end{array}$ & $\begin{array}{l}\text { Tamanho da amostra } \\
\text { muito reduzido. Limi- } \\
\text { tação na interpretação } \\
\text { dos resultados, pois o } \\
\text { estudo foi encerrado } \\
\text { antes do previsto. }\end{array}$ \\
\hline $\begin{array}{l}\text { Gamelin et } \\
\text { al. }^{16} \\
2007\end{array}$ & $\begin{array}{l}\text { Ensaio clínico } \\
\text { prospectivo }\end{array}$ & $\begin{array}{l}135 \text { pacientes } \\
\text { adultos ( } 93 \text { homens } \\
\text { e } 42 \text { mulheres), com } \\
\text { idade entre } 30 \text { e } 80 \\
\text { anos, com câncer de } \\
\text { cólon e reto, tratados } \\
\text { com regime quimio- } \\
\text { terápico baseado em } \\
\text { oxaliplatina. }\end{array}$ & $\begin{array}{l}\text { National Cancer } \\
\text { Institute Common } \\
\text { Toxicity Criteria } \\
\text { (NCI-CTC) versão } 3\end{array}$ & $\begin{array}{l}\text { Pacientes experimen- } \\
\text { taram parestesia e } \\
\text { disestesia nas extremi- } \\
\text { dades e na região oral } \\
\text { e perioral, disetesia } \\
\text { faringolaringeal, di- } \\
\text { minuição dos reflexos } \\
\text { profundos, dificuldade } \\
\text { na realização das } \\
\text { AVD's e incapacidade } \\
\text { funcional. }\end{array}$ & $\begin{array}{l}\text { Os autores estudaram a } \\
\text { fisiopatologia da neuro- } \\
\text { patia periférica secundária } \\
\text { à oxaliplatina, além da } \\
\text { propensão genética para } \\
\text { ocorrência deste agravo, e } \\
\text { sugeriram testes genéticos } \\
\text { para prevençấo desta. }\end{array}$ & $\begin{array}{l}\text { Não foca em detalhes } \\
\text { sobre a neuropatia } \\
\text { periférica secundária } \\
\text { à oxaliplatina, como } \\
\text { sintomas, duraçáo e } \\
\text { localizaçăo. }\end{array}$ \\
\hline
\end{tabular}


Tabela 1

(continuação)

\begin{tabular}{|c|c|c|c|c|c|c|}
\hline $\begin{array}{c}\text { Autores e } \\
\text { Ano de } \\
\text { publicaçáo }\end{array}$ & $\begin{array}{l}\text { Delineamento } \\
\text { do estudo }\end{array}$ & Amostra & Instrumentos & Resultados & Discussão & Comentários \\
\hline $\begin{array}{l}\text { Pietrangeli } \\
\text { et al. }{ }^{17} \\
2006\end{array}$ & Ensaio clínico & $\begin{array}{l}31 \text { pacientes, com } \\
\text { idade entre } 42 \text { e } 73 \\
\text { anos, com câncer } \\
\text { colorretal avançado, } \\
\text { tratados com } \\
\text { regimes baseados em } \\
\text { oxaliplatina. }\end{array}$ & $\begin{array}{l}\text { Exame neurológico/ } \\
\text { EMG }\end{array}$ & $\begin{array}{l}\text { Pacientes relataram } \\
\text { disestesia distal, em } \\
\text { região perioral e larin- } \\
\text { gofaringeal induzida } \\
\text { ou aumentada pelo } \\
\text { frio, de curta duraçáo. } \\
\text { No exame neurológico } \\
\text { foram observados } \\
\text { hiporreflexia dos } \\
\text { tendōes profundos e } \\
\text { hipopalestesia. Sinto- } \\
\text { mas persistiram por } 7 \\
\text { meses após interrupçáo } \\
\text { do tratamento. }\end{array}$ & $\begin{array}{l}\text { Os resultados clínicos e } \\
\text { neurofisiológicos demons- } \\
\text { traram que a reversi- } \\
\text { bilidade da neuropatia } \\
\text { periférica relacionada à } \\
\text { oxaliplatina depende da } \\
\text { dose administrada e do } \\
\text { tempo de observaçáo. A } \\
\text { neuropatia crônica não é } \\
\text { facilmente reversível após } \\
\text { o término do tratamento. }\end{array}$ & $\begin{array}{l}\text { Descriçáo detalhada } \\
\text { dos sinais, sintomas, } \\
\text { intensidade e duraçáo } \\
\text { da neuropatia periférica } \\
\text { secundária à oxali- } \\
\text { platina. Tamanho da } \\
\text { amostra reduzido. }\end{array}$ \\
\hline $\begin{array}{l}\text { Attal et } \\
\text { al. }{ }^{20} \\
2009\end{array}$ & $\begin{array}{l}\text { Ensaio clínico } \\
\text { prospectivo }\end{array}$ & $\begin{array}{l}48 \text { pacientes adultos } \\
\text { ( } 33 \text { homens e } 15 \\
\text { mulheres), com } \\
\text { idade entre } 37 \text { e } 78 \\
\text { anos, a maioria deles } \\
\text { com câncer de cólon } \\
\text { e reto, divididos } \\
\text { em dois grupos: } \\
\text { pacientes tratados } \\
\text { com oxaliplatina ou } \\
\text { cisplatina. }\end{array}$ & $\begin{array}{l}\text { Neuropathic Pain } \\
\text { Symptom Inventory } \\
\text { (NPSI)/ Quantitative } \\
\text { Sensory Testing } \\
\text { (QST)/ } \\
\text { National Cancer } \\
\text { Institute Common } \\
\text { Toxicity Criteria } \\
\text { (NCI-CTC) }\end{array}$ & $\begin{array}{l}\text { Pacientes experimen- } \\
\text { taram parestesia, dises- } \\
\text { tesia e dor em mãos e } \\
\text { pés induzida pelo frio, } \\
\text { hiperalgesia relaciona- } \\
\text { da ao frio,diminuição } \\
\text { ou ausência de reflexos } \\
\text { profundos, ataxia pro- } \\
\text { prioceptiva e déficit de } \\
\text { percepção vibratória. }\end{array}$ & $\begin{array}{l}\text { Os autores sugeriram que } \\
\text { a hiperalgesia relacionada } \\
\text { ao frio é um marcador } \\
\text { eficiente para o desenvol- } \\
\text { vimento da neuropatia } \\
\text { associada à oxaliplatina. } \\
\text { Indicaram o uso do QST } \\
\text { em combinaçáo com a } \\
\text { avaliaçăo dos sintomas } \\
\text { neurológicos para identi- } \\
\text { ficaçáo de pacientes com } \\
\text { alto risco de neurotoxici- } \\
\text { dade crônica. }\end{array}$ & $\begin{array}{l}\text { Bom estudo, porém } \\
\text { tamanho da amostra } \\
\text { reduzido. }\end{array}$ \\
\hline $\begin{array}{l}\text { Grothey et } \\
\text { al. }^{21} \\
2010\end{array}$ & $\begin{array}{l}\text { Ensaio clínico } \\
\text { prospectivo, } \\
\text { randomizado }\end{array}$ & $\begin{array}{l}102 \text { pacientes adul- } \\
\text { tos ( } 54 \text { homens e } 48 \\
\text { mulheres), com cân- } \\
\text { cer de cólon estágio } \\
\text { II e III, tratados com } \\
\text { regimes baseados em } \\
\text { oxaliplatina. }\end{array}$ & $\begin{array}{l}\text { National Cancer } \\
\text { Institute Common } \\
\text { Toxicity Criteria } \\
\text { (NCI-CTC), versão } \\
\text { 3/ Oxaliplatin- } \\
\text { Specific Neurotoxicity } \\
\text { Scale }\end{array}$ & $\begin{array}{l}\text { Pacientes apresentaram } \\
\text { sintomas relacionados } \\
\text { à neuropatia aguda, } \\
\text { como hipersensibilida- } \\
\text { de ao frio, desconforto } \\
\text { na garganta, cáibras } \\
\text { musculares, dormência } \\
\text { e formigamento em } \\
\text { mãos e pés. }\end{array}$ & $\begin{array}{l}\text { Os autores sugeriram } \\
\text { que aplicaçôes de Ca/ } \\
\text { Mg reduzem as cáibras } \\
\text { musculares, mas não } \\
\text { diminuem a sensibilidade } \\
\text { ao frio. Notaram uma } \\
\text { melhora dos sintomas } \\
\text { após o primeiro ciclo, em } \\
\text { comparação com os ciclos } \\
\text { seguintes. }\end{array}$ & $\begin{array}{l}\text { Apresenta poucos } \\
\text { detalhes sobre tipo } \\
\text { duraçáo e localizaçáo } \\
\text { da neuropatia periférica } \\
\text { secundária à oxalipla- } \\
\text { tina. }\end{array}$ \\
\hline $\begin{array}{l}\text { Argyriou et } \\
\text { al. }^{22} \\
2006\end{array}$ & $\begin{array}{l}\text { Ensaio clínico } \\
\text { randomizado }\end{array}$ & $\begin{array}{l}40 \text { pacientes ( } 25 \\
\text { homens e } 15 \\
\text { mulheres), com } \\
\text { câncer de cólon } \\
\text { avançado, tratados } \\
\text { com oxaliplatina, } \\
\text { divididos em dois } \\
\text { grupos: pacientes } \\
\text { que receberam ou } \\
\text { não oxcarbazepina. }\end{array}$ & $\begin{array}{l}\text { Neurologic Sympton } \\
\text { Score (NSS)/ } \\
\text { Neurologic Disability } \\
\text { Score (NDS) }\end{array}$ & $\begin{array}{l}\text { Pacientes experimenta- } \\
\text { ram sintomas sensoriais } \\
\text { positivos e negativos, } \\
\text { sendo que o grupo que } \\
\text { recebeu oxcarbazepina } \\
\text { apresentou menos } \\
\text { sintomas que o grupo } \\
\text { controle. }\end{array}$ & $\begin{array}{l}\text { Os autores sugeriram } \\
\text { que a oxcarbazepina tem } \\
\text { um efeito neuroprotetor } \\
\text { importante, atuando de } \\
\text { forma efetiva na preven- } \\
\text { ção da neuropatia perifé- } \\
\text { rica crônica secundária à } \\
\text { oxaliplatina. }\end{array}$ & $\begin{array}{l}\text { Tamanho da amostra } \\
\text { reduzido. Apresenta os } \\
\text { resultados de forma su- } \\
\text { perficial, não descreve } \\
\text { os sinais e sintomas e } \\
\text { outros aspectos impor- } \\
\text { tantes da neuropatia } \\
\text { associada à oxaliplatina. }\end{array}$ \\
\hline $\begin{array}{l}\text { Kono et } \\
\text { al. }{ }^{23} \\
2009\end{array}$ & $\begin{array}{l}\text { Estudo } \\
\text { retrospectivo }\end{array}$ & $\begin{array}{l}90 \text { pacientes ( } 52 \\
\text { homens e } 38 \\
\text { mu-lheres), com } \\
\text { idade entre } 36 \text { e } \\
87 \text { anos, com câncer } \\
\text { colorretal avançado, } \\
\text { tratados com } \\
\text { regimes qui-mio- } \\
\text { terápicos baseados } \\
\text { em oxali-platina, } \\
\text { divididos em grupos } \\
\text { para receber ou não } \\
\text { goshajinkigan. }\end{array}$ & $\begin{array}{l}\text { Neurotoxicity Criteria } \\
\text { of Debiopharm } \\
\text { (DEB-NTC) }\end{array}$ & $\begin{array}{l}\text { Pacientes apresentaram } \\
\text { parestesia e disestesia } \\
\text { das extremidades } \\
\text { induzidas pelo frio, dor } \\
\text { e disfunção sensorial. } \\
\text { Nas doses mais eleva- } \\
\text { das foi observada inca- } \\
\text { pacidade funcional. }\end{array}$ & $\begin{array}{l}\text { Os autores sugeriram } \\
\text { que o goshajinkigan tem } \\
\text { efeito neuroprotetor na } \\
\text { neuropatia periférica } \\
\text { secundária à oxaliplatina } \\
\text { em pacientes com câncer } \\
\text { de cólon e reto. }\end{array}$ & $\begin{array}{l}\text { Tamanho da amostra } \\
\text { reduzido. Desenho de } \\
\text { estudo retrospectivo. }\end{array}$ \\
\hline
\end{tabular}


Tabela 1

(continuação)

\begin{tabular}{|c|c|c|c|c|c|c|}
\hline $\begin{array}{c}\text { Autores e } \\
\text { Ano de } \\
\text { publicaçáo }\end{array}$ & $\begin{array}{l}\text { Delineamento } \\
\text { do estudo }\end{array}$ & Amostra & Instrumentos & Resultados & Discussáo & Comentários \\
\hline $\begin{array}{l}\text { Binder et } \\
\text { al. }^{24} \\
2007\end{array}$ & $\begin{array}{l}\text { Ensaio clínico } \\
\text { prospectivo }\end{array}$ & $\begin{array}{l}16 \text { pacientes adultos, } \\
\text { com idade entre } 39 \\
\text { a } 75 \text { anos, com diag- } \\
\text { nóstico de câncer } \\
\text { de cólon, esôfago e } \\
\text { gástrico, divididos } \\
\text { em dois grupos: } \\
\text { pacientes com e sem } \\
\text { queixa álgica. }\end{array}$ & $\begin{array}{l}\text { Quantitative } \\
\text { SensoryTesting } \\
\text { (QST)/ Questionário } \\
\text { de Dor McGill } \\
\text { (versão alemã)/ } \\
\text { Oxaliplatin-Specific } \\
\text { Neurotoxicity Scale }\end{array}$ & $\begin{array}{l}56.2 \% \text { dos pacientes } \\
\text { apresentaram queixa } \\
\text { de dor associada ao } \\
\text { frio, provocada pelo } \\
\text { ambiente com baixas } \\
\text { temperaturas e/ou } \\
\text { contato com objetos, } \\
\text { líquidos ou ar frio. }\end{array}$ & $\begin{array}{l}\text { Os autores sugeriram } \\
\text { que os sintomas de dor } \\
\text { relacionados à neuro- } \\
\text { toxicidade da oxalipla- } \\
\text { tina ocorrem devido à } \\
\text { sensibilizaçáo do sistema } \\
\text { nociceptivo periférico e } \\
\text { central. }\end{array}$ & $\begin{array}{l}\text { Bom estudo, porém } \\
\text { tamanho da amostra } \\
\text { muito reduzido. }\end{array}$ \\
\hline $\begin{array}{l}\text { Lehky et } \\
\text { al. }^{25} \\
2004\end{array}$ & $\begin{array}{l}\text { Ensaio clínico } \\
\text { fase I }\end{array}$ & $\begin{array}{l}50 \text { pacientes ( } 37 \text { ho- } \\
\text { mens e } 13 \text { mulheres), } \\
\text { com idade entre } 27 \text { e } \\
33 \text { anos, com câncer } \\
\text { colorretal avançado, } \\
\text { tratados com regime } \\
\text { quimioterápico base- } \\
\text { ado em oxaliplatina. }\end{array}$ & $\begin{array}{l}\text { National Cancer } \\
\text { Institute Common } \\
\text { Toxicity Criteria } \\
\text { (NCI-CTC) }\end{array}$ & $\begin{array}{l}\text { Pacientes apresenta- } \\
\text { ram neurotoxicidade } \\
\text { aguda secundária a } \\
\text { oxaliplatina, com } \\
\text { parestesia induzida } \\
\text { pelo frio, dormência na } \\
\text { regiáo perioral, aperto } \\
\text { na laringofaringe e } \\
\text { mandíbula e câimbras } \\
\text { musculares. Parestesia } \\
\text { em máos e pés persis- } \\
\text { tiram depois do oitavo } \\
\text { ciclo de quimioterapia, } \\
\text { caracterizando neuro- } \\
\text { patia crônica. }\end{array}$ & $\begin{array}{l}\text { Os autores sugeriram que } \\
\text { a neurotoxicidade aguda } \\
\text { secundária a oxaliplatina } \\
\text { caracteriza-se pela hipere- } \\
\text { xcitabilidade do nervo pe- } \\
\text { riférico, assemelhando-se } \\
\text { às manifestaçóes clínicas } \\
\text { da neuromiotonia. }\end{array}$ & $\begin{array}{l}\text { Tamanho da amostra } \\
\text { reduzido. }\end{array}$ \\
\hline $\begin{array}{l}\text { Park et al. }{ }^{26} \\
2010\end{array}$ & Coorte & $\begin{array}{l}15 \text { pacientes (12 ho- } \\
\text { mens e } 3 \text { mulheres) } \\
\text { com câncer color- } \\
\text { retal estágio II, III } \\
\text { e IV, tratados com } \\
\text { regimes baseados em } \\
\text { oxaliplatina. }\end{array}$ & $\begin{array}{l}\text { National Cancer } \\
\text { Institute Common } \\
\text { Toxicity Criteria } \\
\text { (NCI-CTC), versão } 3 \\
\text { /Oxaliplatin-Specific } \\
\text { Neurotoxicity Scale }\end{array}$ & $\begin{array}{l}\text { Todos os pacientes } \\
\text { experimentaram } \\
\text { neurotoxicidade } \\
\text { aguda relacionada à } \\
\text { oxaliplatina. Sintomas } \\
\text { relatados: cáibras mus- } \\
\text { culares e fasciculaçóes } \\
\text { induzidas pelo frio nas } \\
\text { mãos e pés, disestesia } \\
\text { faringolaringeal, hiper- } \\
\text { sensibilidade ao frio, } \\
\text { parestesia, dor e rigidez } \\
\text { mandibular. }\end{array}$ & $\begin{array}{l}\text { Os autores sugeriram que } \\
\text { a oxaliplatina afeta a exci- } \\
\text { tabilidade nervosa através } \\
\text { de mecanismos voltagem- } \\
\text {-dependentes. Sugeriram } \\
\text { também a busca de } \\
\text { estratégias terapêuticas } \\
\text { através da modulação dos } \\
\text { canais de } \mathrm{Na}+\text {. }\end{array}$ & $\begin{array}{l}\text { Tamanho da amostra } \\
\text { reduzido. Apresenta } \\
\text { poucos detalhes sobre } \\
\text { a neuropatia periférica } \\
\text { secundária à oxalipla- } \\
\text { tina. }\end{array}$ \\
\hline $\begin{array}{l}\text { Delius et } \\
\text { al. }^{27} \\
2007\end{array}$ & $\begin{array}{l}\text { Ensaio clínico } \\
\text { prospectivo, } \\
\text { randomizado, } \\
\text { multicêntrico, } \\
\text { fase II }\end{array}$ & $\begin{array}{l}36 \text { pacientes (18 } \\
\text { homens e } 18 \text { mulhe- } \\
\text { res), com idade entre } \\
36 \text { e } 82 \text { anos, com } \\
\text { câncer colorretal, } \\
\text { tratados com oxa- } \\
\text { liplatina, divididos } \\
\text { em dois grupos: } \\
\text { para receber ou nâo } \\
\text { carbamazepina. }\end{array}$ & $\begin{array}{l}\text { Neurotoxicity } \\
\text { grading scale of Levi / } \\
\text { Testes para avaliação } \\
\text { proprioceptiva e } \\
\text { exteroceptiva. }\end{array}$ & $\begin{array}{l}\text { Os sintomas neuroló- } \\
\text { gicos mais frequentes } \\
\text { foram parestesia e dor- } \\
\text { mência em pés e dedos. } \\
\text { Ao exame físico, foram } \\
\text { observadas redução da } \\
\text { percepção vibratória } \\
\text { nos membros inferiores } \\
\text { e diminuiçáa ou } \\
\text { ausência dos reflexos } \\
\text { tendíneos profundos. } \\
\text { Não houve perda de } \\
\text { força muscular signi- } \\
\text { ficativa. }\end{array}$ & $\begin{array}{l}\text { Os autores consideraram } \\
\text { os resultados inconclu- } \\
\text { sivos quanto à eficácia } \\
\text { da carbamazepina na } \\
\text { prevençáo da neuropatia } \\
\text { periférica secundária à } \\
\text { oxaliplatina devido ao } \\
\text { tamanho reduzido da } \\
\text { amostra e baixo poder } \\
\text { estatístico do estudo. }\end{array}$ & $\begin{array}{l}\text { Utilização de boas } \\
\text { escalas para avaliação } \\
\text { neurológica, porém } \\
\text { tamanho da amostra } \\
\text { muito reduzido. }\end{array}$ \\
\hline $\begin{array}{l}\text { Kottshade } \\
\text { et al. } .^{29} \\
2010\end{array}$ & $\begin{array}{l}\text { Ensaio clínico, } \\
\text { randomizado, } \\
\text { prospectivo, } \\
\text { fase III }\end{array}$ & $\begin{array}{l}189 \text { pacientes } \\
\text { adultos ( } 34 \text { homens } \\
\text { e } 155 \text { mulheres), } \\
\text { com diagnóstico de } \\
\text { câncer, tratados com } \\
\text { diferentes agentes } \\
\text { quimioterápicos, in- } \\
\text { cluindo oxaliplatina, } \\
\text { divididos em dois } \\
\text { grupos: pacientes } \\
\text { que receberam ou } \\
\text { náo vitamina E. }\end{array}$ & \begin{tabular}{|l|} 
National \\
Cancer Institute \\
Common Toxicity \\
Criteria(NCI-CTC) \\
versão 3/ Neuropathy \\
Specif Questionary \\
Symptom
\end{tabular} & $\begin{array}{l}\text { Pacientes experimenta- } \\
\text { ram dormência e for- } \\
\text { migamento em mãos } \\
\text { e pés, dor em mãos e } \\
\text { pés, hipoestesia, difi- } \\
\text { culdade na marcha, na } \\
\text { realizaçáo de atividades } \\
\text { funcionais e atividades } \\
\text { de coordenaçấo motora } \\
\text { fina. }\end{array}$ & $\begin{array}{l}\text { Os autores não encontra- } \\
\text { ram associaçáo entre uso } \\
\text { de vitamina E e melhora } \\
\text { da neuropatia periférica } \\
\text { secundária ao uso de } \\
\text { agentes quimioterápicos. }\end{array}$ & $\begin{array}{l}\text { Poderia abordar mais } \\
\text { detalhes sobre tipo, } \\
\text { localizaçấo, duração e } \\
\text { sintomas da neuropatia } \\
\text { periférica relacionada à } \\
\text { quimioterapia. }\end{array}$ \\
\hline
\end{tabular}


Tabela 1

(continuação)

\begin{tabular}{|c|c|c|c|c|c|c|}
\hline $\begin{array}{c}\text { Autores e } \\
\text { Ano de } \\
\text { publicaçáo }\end{array}$ & $\begin{array}{c}\text { Delineamento } \\
\text { do estudo }\end{array}$ & Amostra & Instrumentos & Resultados & Discussáo & Comentários \\
\hline $\begin{array}{l}\text { Gramont et } \\
\text { al. }^{30} \\
2000\end{array}$ & $\begin{array}{l}\text { Ensaio clínico, } \\
\text { randomizado, } \\
\text { fase III }\end{array}$ & $\begin{array}{l}420 \text { pacientes ( } 249 \\
\text { homens e } 171 \\
\text { mulheres), com } \\
\text { idade entre } 18 \text { e } 75 \\
\text { anos, com câncer de } \\
\text { cólon e reto, com } \\
\text { metástase. }\end{array}$ & $\begin{array}{l}\text { National Cancer } \\
\text { Institute Common } \\
\text { Toxicity Criteria } \\
\text { (NCI-CTC) }\end{array}$ & $\begin{array}{l}18 \% \text { dos indivíduos } \\
\text { tratados com oxalipla- } \\
\text { tina apresentaram to- } \\
\text { xicidade neurosensitiva } \\
\text { grau } 3 \text { em alguma fase } \\
\text { do tratamento. Esta foi } \\
\text { reversível em } 74 \% \text { dos } \\
\text { pacientes. }\end{array}$ & $\begin{array}{l}\text { Os resultados do estudo } \\
\text { demonstraram que, apesar } \\
\text { da toxicidade neurosensi- } \\
\text { tiva ser um fator limitante } \\
\text { para o uso de doses mais } \\
\text { elevadas da droga, esta é } \\
\text { reversível na maioria dos } \\
\text { casos. }\end{array}$ & $\begin{array}{l}\text { Bom estudo rando- } \\
\text { mizado. Os autores } \\
\text { associam com clareza } \\
\text { os resultados com as } \\
\text { evidências já descritas } \\
\text { na literatura. }\end{array}$ \\
\hline $\begin{array}{l}\text { Lecomte et } \\
\text { al. }^{31} \\
2006\end{array}$ & \begin{tabular}{|l|} 
Estudo \\
retrospectivo
\end{tabular} & $\begin{array}{l}64 \text { pacientes ( } 35 \\
\text { homens e } 29 \\
\text { mulheres), com } \\
\text { câncer gastrointes- } \\
\text { tinal, tratados com } \\
\text { regimes baseados em } \\
\text { oxaliplatina. }\end{array}$ & $\begin{array}{l}\text { Oxaliplatin-Specific } \\
\text { Neurotoxicity Scale }\end{array}$ & $\begin{array}{l}42 \% \text { dos pacientes } \\
\text { apresentaram parestesia } \\
\text { e disestesia de curta } \\
\text { duração, } 27 \% \text { deles } \\
\text { experimentaram pa- } \\
\text { restesia e disestesia que } \\
\text { persistiram entre os ci- } \\
\text { clos de quimioterapia, } \\
\text { e } 23 \% \text { dos pacientes } \\
\text { apresentaram incapaci- } \\
\text { dade funcional. }\end{array}$ & $\begin{array}{l}\text { Os resultados do estudo } \\
\text { sugeriram que o polimor- } \\
\text { fismo do gene GSTP1 } \\
\text { pode aumentar o risco } \\
\text { de neuropatia severa em } \\
\text { pacientes com câncer } \\
\text { gastrointestinal em trata- } \\
\text { mento com quimioterapia } \\
\text { baseada em oxaliplatina. }\end{array}$ & $\begin{array}{l}\text { Tamanho da amostra } \\
\text { reduzido. Náo foca em } \\
\text { detalhes sobre a neuro- } \\
\text { patia periférica. }\end{array}$ \\
\hline $\begin{array}{l}\text { Petrioli et } \\
\mathrm{al.}^{32} \\
2007\end{array}$ & $\begin{array}{l}\text { Ensaio clínico, } \\
\text { randomizado, } \\
\text { prospectivo }\end{array}$ & $\begin{array}{l}64 \text { pacientes adultos } \\
\text { ( } 39 \text { homens e } 25 \\
\text { mulheres), com } \\
\text { idade entre } 42 \text { e } 70 \\
\text { anos, com câncer } \\
\text { de cólon estágio II } \\
\text { ou III e/ou câncer } \\
\text { gástrico, tratados } \\
\text { com oxaliplatina. }\end{array}$ & $\begin{array}{l}\text { National Cancer } \\
\text { Institute Common } \\
\text { Toxicity Criteria, } \\
\text { versão } 2\end{array}$ & $\begin{array}{l}\text { Pacientes apresentaram } \\
\text { parestesia e disestesia } \\
\text { distal induzida pelo } \\
\text { frio, aumentando com } \\
\text { a dose cumulativa da } \\
\text { oxaliplatina. Alguns } \\
\text { pacientes apresentaram } \\
\text { incapacidade funcional } \\
\text { com doses mais } \\
\text { elevadas. Depois de } 6 \\
\text { meses,baixa incidência } \\
\text { de neurotoxicidade } \\
\text { severa. }\end{array}$ & $\begin{array}{l}\text { Os autores associaram } \\
\text { a baixa incidência de } \\
\text { neurotoxicidade severa } \\
\text { nos seis meses de segui- } \\
\text { mento à dose cumulativa } \\
\text { máxima de } 1.020 \mathrm{mg} / \mathrm{m} 2 \\
\text { recebida pelos pacientes. } \\
\text { Sugeriram que a admi- } \\
\text { nistração da oxaliplatina } \\
\text { durante tempo de infusão } \\
\text { mais prolongado resulta } \\
\text { em diminuiçấo da neuro- } \\
\text { toxicidade. }\end{array}$ & $\begin{array}{l}\text { Tamanho da amostra } \\
\text { reduzido. }\end{array}$ \\
\hline $\begin{array}{l}\text { Park et al. }{ }^{33} \\
2009\end{array}$ & $\begin{array}{l}\text { Ensaio clínico } \\
\text { prospectivo }\end{array}$ & $\begin{array}{l}25 \text { pacientes adultos } \\
\text { (14 homense } 11 \text { mu- } \\
\text { lheres), com idade } \\
\text { entre } 22 \text { e } 77 \text { anos, } \\
\text { com câncer de cólon } \\
\text { e reto estágio II, III } \\
\text { ou IV, tratados com } \\
\text { regimes quimioterá- } \\
\text { picos baseados em } \\
\text { oxaliplatina. }\end{array}$ & \begin{tabular}{|l|} 
National Cancer \\
Institute Common \\
Toxicity Criteria \\
(NCI-CTC), versão \\
3 Oxaliplatin Specific \\
Neurotoxicity Scale
\end{tabular} & $\begin{array}{l}\text { Pacientes apresentaram } \\
\text { parestesia associada ao } \\
\text { frio, disestesia, sensa- } \\
\text { çâo de aperto ou dor } \\
\text { na mandíbula, cãibras } \\
\text { musculares ou fascicu- } \\
\text { laçôes. Em alguns casos } \\
\text { houve incapacidade } \\
\text { funcional. }\end{array}$ & $\begin{array}{l}\text { Os autores sugeriram } \\
\text { uma associação entre as } \\
\text { manifestaçôes aguda e } \\
\text { crônica da neuropatia } \\
\text { periférica induzida pela } \\
\text { oxaliplatina. }\end{array}$ & $\begin{array}{l}\text { Tamanho da amostra } \\
\text { redu-zido. Não apre- } \\
\text { senta detalhes sobre os } \\
\text { sintomas da neuro-pa- } \\
\text { tia periférica secundária } \\
\text { à oxaliplatina. }\end{array}$ \\
\hline $\begin{array}{l}\text { Tofthagen } \\
\text { et al. }{ }^{34} \\
2011\end{array}$ & $\begin{array}{l}\text { Ensaio clínico } \\
\text { prospectivo }\end{array}$ & $\begin{array}{l}109 \text { pacientes ( } 40 \\
\text { homens e } 69 \text { mu- } \\
\text { lheres), com idade } \\
\text { entre } 18 \text { e } 90 \text { anos, } \\
\text { com diferentes tipos } \\
\text { de câncer, incluindo } \\
\text { câncer de cólon, } \\
\text { em tratamento com } \\
\text { oxaliplatina e outras } \\
\text { drogas. }\end{array}$ & $\begin{array}{l}\text { Chemotherapy } \\
\text { Induced Peripheral } \\
\text { Neuropathy } \\
\text { Assessment Tool } \\
\text { (CIPNAT) }\end{array}$ & $\begin{array}{l}\text { Pacientes apresentaram } \\
\text { dormência e formi- } \\
\text { gamento em máos e } \\
\text { pés, sensibilidade ao } \\
\text { frio, dor muscular } \\
\text { e articular, fraqueza } \\
\text { muscular, alteração do } \\
\text { equilíbrio, alteraçáo na } \\
\text { marcha e dificuldade } \\
\text { para dirigir. }\end{array}$ & $\begin{array}{l}\text { Os autores avaliaram o } \\
\text { risco de queda decor- } \\
\text { rente dos sintomas da } \\
\text { neuropatia periférica em } \\
\text { pacientes tratados com } \\
\text { quimioterapia e sugeriram } \\
\text { a utilizaçáo de medidas } \\
\text { objetivas para avaliação } \\
\text { funcional. }\end{array}$ & $\begin{array}{l}\text { Bom estudo. Utiliza } \\
\text { uma boa escala para } \\
\text { avaliação funcional em } \\
\text { pacientes que realizam } \\
\text { quimioterapia com } \\
\text { diferentes agentes } \\
\text { antineoplásicos. }\end{array}$ \\
\hline
\end{tabular}

A análise dos dados referentes à ocorrência de fraqueza muscular mostra divergência entre os autores. Em uma pesquisa ${ }^{13}$, ao exame clínico com pacientes que cursaram com neuropatia grave, foi descrita a presença de fraqueza muscular suave a moderada, envolvendo principalmente os músculos distais, como os extenso- res do hálux e os abdutores dos dedos. Outros autores ${ }^{1}$ relataram o caso de um paciente que desenvolveu uma síndrome sensoriomotora progressiva após a quarta dose de oxaliplatina, a qual acarretou uma fraqueza profunda nos membros superiores e inferiores, sem comprometimento da musculatura respiratória. Em discordância com 
esses autores, em outros estudos ${ }^{9,27}$, foi encontrada pouca ou nenhuma alteração de força muscular, e os autores ${ }^{27}$ associaram esse fato ao não envolvimento de neurônios motores na toxicidade crônica desta droga, já que esta é puramente sensitiva. Essa fraqueza, provavelmente, deve-se ao fato de a oxaliplatina comprometer os nervos eferentes, prejudicando a sua função de estimular os órgãos efetuadores, que são parte inerente dos músculos.

Nos casos mais graves, ataxia sensitiva pode ocorrer nos pacientes submetidos a esse tratamento. Autores ${ }^{20}$ verificaram a ocorrência de ataxia proprioceptiva em $17 \%$ dos pacientes avaliados 12,2 meses após o término da quimioterapia com oxaliplatina. Esse resultado também foi descrito em dois estudos ${ }^{9,33}$ realizados pelo mesmo grupo de pesquisadores, que descreveram presença de ataxia sensitiva nos indivíduos que evoluíram com neuropatia periférica grave. Em outra pesquisa ${ }^{2}$, foi encontrada uma incidência bem mais baixa desse sintoma, o qual foi descrito em menos de 5\% dos pacientes com neuropatia grau 3.

Autores ${ }^{13}$ citaram ainda a ocorrência de marcha instável, como consequência da ataxia sensitiva, em $8 \%$ dos indivíduos estudados. Em pesquisa ${ }^{34}$ que tinha como objetivo avaliar o risco de queda em pacientes com neuropatia secundária à quimioterapia, a dificuldade na marcha foi descrita como um dos efeitos da terapia com oxaliplatina. Essa forma de ataxia ocorre quando há comprometimento da sensibilidade cinético-postural. Quando as informaçóes transmitidas ao sistema nervoso central por receptores situados nas articulações e tendôes são insuficientes, não há noção perfeita da posição dos segmentos do corpo e suas modificaçóes, o que acarreta uma marcha alterada, caracterizada por andar inseguro e passos irregulares. Processos patológicos que atingem as raízes dorsais dos nervos espinhais são as causas mais frequentes deste $\operatorname{agravo}^{28}$.

A realização dessta revisão de literatura trouxe a possibilidade de disponibilizar para a comunidade acadêmica e profissional uma síntese das informaçôes contidas nos estudos relevantes publicados nos últimos seis anos sobre a neuropatia periférica em pacientes com câncer colorretal tratados com oxaliplatina, contribuindo para sistematizar o conhecimento acerca deste.
Tabela 2

Incidência dos sintomas da neuropatia periférica em pacientes com câncer colorretal submetidos à quimioterapia com oxaliplatina nos estudos revisados

\begin{tabular}{|c|c|c|}
\hline Sintomas & Estudos & Incidências \\
\hline \multirow[t]{4}{*}{ Parestesia } & Leonard et $\mathrm{al}^{1}$ & $94,3 \%$ \\
\hline & Ishibashi et $\mathrm{al}^{14}$ & $96,0 \%$ \\
\hline & Chay et a ${ }^{15}$ & $59,3 \%$ \\
\hline & Land et $\mathrm{al}^{2}$ & $19,5 \%$ \\
\hline \multirow[t]{3}{*}{ Disestesia } & Gamelin et $\mathrm{al}^{16}$ & $50,4 \%$ \\
\hline & Pietrangeli et a ${ }^{17}$ & $72,2 \%$ \\
\hline & Gramont et $\mathrm{al}^{30}$ & $67,5 \%$ \\
\hline \multirow{6}{*}{$\begin{array}{l}\text { Parestesia/Disestesia } \\
\text { induzidas pelo frio }\end{array}$} & Attal et $\mathrm{al}^{20}$ & $96,0 \%$ \\
\hline & Leonard et $\mathrm{al}^{1}$ & $87,2 \%$ \\
\hline & Wilson et al ${ }^{5}$ & $100,0 \%$ \\
\hline & Hill et $\mathrm{al}^{8}$ & $100,0 \%$ \\
\hline & Petrioli et $\mathrm{al}^{10}$ & $75,0 \%$ \\
\hline & Pietrangeli et al ${ }^{17}$ & $72,0 \%$ \\
\hline \multirow[t]{4}{*}{ Dor induzida pelo frio } & Binder et $\mathrm{a}^{24}$ & $56,3 \%$ \\
\hline & Attal et $\mathrm{al}^{20}$ & $96,0 \%$ \\
\hline & Leonard et al ${ }^{1}$ & $80,0 \%$ \\
\hline & Land et $\mathrm{al}^{2}$ & $26,0 \%$ \\
\hline \multirow[t]{4}{*}{ Espasmos musculares } & Leonard et $\mathrm{al}^{1}$ & $60,0 \%$ \\
\hline & Wilson et al ${ }^{5}$ & $70,0 \%$ \\
\hline & Lehky et $\mathrm{al}^{25}$ & $70,0 \%$ \\
\hline & Park et $\mathrm{al}^{9}$ & $13,0 \%$ \\
\hline \multirow[t]{4}{*}{ Arreflexia e hiporreflexia } & Attal et $\mathrm{al}^{20}$ & $50,0 \%$ \\
\hline & Pietrangeli et al ${ }^{17}$ & $76,0 \%$ \\
\hline & Argyriou et $\mathrm{al}^{22}$ & $40,0 \%$ \\
\hline & Gramont et a ${ }^{30}$ & $11,5 \%$ \\
\hline \multirow{2}{*}{$\begin{array}{l}\text { Apalestesia e } \\
\text { hipopalesetesia }\end{array}$} & Pietrangeli et al ${ }^{17}$ & $100,0 \%$ \\
\hline & Argyriou et $\mathrm{al}^{22}$ & $64,0 \%$ \\
\hline \multirow[t]{3}{*}{ Ataxia sensorial } & Attal et $\mathrm{al}^{20}$ & $17,0 \%$ \\
\hline & Land et $\mathrm{al}^{2}$ & $5,0 \%$ \\
\hline & Argyriou et $\mathrm{al}^{22}$ & $8,0 \%$ \\
\hline
\end{tabular}

\section{CONCLUSÃO}

Pacientes com câncer colorretal submetidos à quimioterapia com regimes baseados em oxaliplatina geralmente evoluem com neuropatia periférica. As principais manifestaçôes clínicas relacionadas a esse agravo são as alteraçôes de sensibilidade, principalmente parestesias e disetesias, hipersensibilidade ao frio, dor, contraçóes musculares, diminuição ou ausência de reflexos tendíneos 
e, nos quadros mais graves, incapacidade funcional. Torna-se essencial que os profissionais de saúde envolvidos nos cuidados paliativos desses pacientes estejam atentos a todas essas possíveis alteraçóes, assim como seu manejo, com o intuito de minimizar o sofrimento destes e melhorar sua qualidade de vida. Recomendam-se novos estudos com a finalidade de ampliar o conhecimento acerca desse agravo.

\section{REFERÊNCIAS}

1.Leonard GD, Wright MA, Quinn MG, Fioravanti S, Harold N, Schuler $\mathrm{B}$, et al. Survey of oxaliplatin-associated neurotoxicity using an interview-based questionnaire in patients with metastatic colorectal cancer. BMC Cancer 2005;5:116-26.

http://dx.doi.org/10.1186/1471-2407-5-116

2.Land SR, Kopec JA, Cecchini RS, Ganz PA, Wieand HS, Colangelo LH, et al. Neurotoxicity from oxaliplatin combined with weekly bolus fluourouracil and leucovorin as surgical adjuvant chemotherapy for stage II and III colon cancer: NSABP C-07. J Clin Oncol 2007;25(16):2205-11.

http://dx.doi.org/10.1200/JCO.2006.08.6652

3.Wang WS, Lin JK, Lin TC, Chen WS, Jiang JK, Wang HS, et al. Oral glutamine is effective for preventing oxaliplatin-induced neuropathy in colorectal cancer. The Oncologist 2007;12(3):312-9.

http://dx.doi.org/10.1634/theoncologist.12-3-312

4.Gamelin E, Gamelin L, Bossi L, Quasthoff S. Clinical aspects and molecular basis of oxaliplatin neurotoxicity: current management and development of preventive measures. Seminars in Oncology 2002;29(15):21-33.

http://dx.doi.org/10.1053/sonc.2002.35525

5.Wilson RH, Lehky T, Thomas RR, Quinn MG, Floeter MK, Grem JL. Acute oxaliplatin-induced peripheral nerve hyperexcitability. J Clin Oncol. 2002;20(7):1767-74.

\section{http://dx.doi.org/10.1200/JCO.2002.07.056}

6.Thierry A, Boni C, Boudiaf L, Navarro M, Tabernero J, Hickish T, et al. Improved Overall Survival with oxaliplatin, fluorouracil and leucovorin as adjuvant treatment in stage II and III colon cancer in the MOSAIC trial. J Clin Oncol 2009;27:3109-16.

http://dx.doi.org/10.1200/JCO.2008.20.6771

7.Mathias C, Feher O, Coutinho A, Paulo M, Hoff P. Manual de Condutas da Sociedade Brasileira de Oncologia Clinica. São Paulo; 2007.

8.Hill A, Bergin P, Hanning F, Thompson P, Findlay M, Damianovich D, et al. Detecting acute neurotoxicity durind platinum chemotherapy by neurophysiological assessment of motor nerve hyperexcitability. BMC Cancer 2010;10(451):1471-2407.

9.Park S, Lin C, Krishnan A, Goldstein D, Friedlander L, Kiernan M. Oxaliplatin-induced neurotoxicity: changes in axonal excitability precede development of neuropathy. Brain 2009;132:2712-23.

http://dx.doi.org/10.1093/brain/awp219

10.Petrioli R, Paolelli L, Marsili S, Civitelli S, Francini E, Cioppa T, et al. Folfox- 4 stop and go and capecitabine manteinance chemotherapy in the treatment of metastatic colorectal cancer. Oncology 2006;70:345-50.

http://dx.doi.org/10.1159/000098107
11.Baek K, Lee J, Park S, Park J, Park Y, Lim H, et al. Oxaliplatin-induced chronic peripheral neurotoxicity: a prospective analysis in patients with colorectal cancer. Cancer Res Treat 2010;42(4):185-90.

http://dx.doi.org/10.4143/crt.2010.42.4.185

12.Kuebler JP, Wieand HS, O'Connell MJ, Smith RE, Colangelo LH, Yothers $\mathrm{G}$, et al. Oxaliplatin combined with weekly bolus fluorouracil and leucovorin as surgical adjuvant chemotherapy for stage II and III colon cancer: results from NSABP C-07. J Clin Oncol 2007;25:2198-204.

http://dx.doi.org/10.1200/JCO.2006.08.2974

13.Argyriou A, Polychronopoulos P, Iconomou G, Koutras A, Makatsoris T, Gerolymos $\mathrm{M}$, et al. Incidence and characteristics of peripheral neuropathy during oxaliplatin-based chemotherapy for metastatic colon cancer. Acta Oncol 2007;46:1131-7.

http://dx.doi.org/10.1080/02841860701355055

14.Ishibashi K, Okada N, Miyazaki T, Sano M, Ishida H. Effect of calcium and magnesium on neurotoxicity and blood platinum concentrations in patients receiving mFOLFOX6 therapy: a prospective randomized study. Int J Clin Oncol 2010;15:82-7.

http://dx.doi.org/10.1007/s10147-009-0015-3

15.Chay WY, Tan SH, Lo YL, Ong YK, Ng HC, Gao F, et al. Use of calcium and magnesium infusions in prevention of oxaliplatin induced sensory neuropathy. Asia- Pac J Clin Oncol 2010;6:270-7.

http://dx.doi.org/10.1111/j.1743-7563.2010.01344.x

16.Gamelin L, Capitain O, Morel A, Dumont A, Traore S, Anne LB, et al. Predictive Factors of Oxaliplatin Neurotoxicity: The Involvement of the Oxalate Outcome Pathway. Clin Cancer Res 2007;13(21):6359-68.

http://dx.doi.org/10.1158/1078-0432.CCR-07-0660

17.Pietrangeli A, Leandri M, Terzoli E, Jandolo B, Garufi C. Persistence of high-dose Oxaliplatin-induced neuropathy at long-term follow-up. Eur Neurol 2006;56:13-6.

http://dx.doi.org/10.1159/000094376

18.Grothey A. Clinical Management of oxaliplatin-associated neurotoxicity. Clin Colorec Cancer 2005;5(1):38-46.

http://dx.doi.org/10.3816/CCC.2005.s.006

19.Pasetto LM, D’Andrea MR, Rossi E, Monfardini S. Oxaliplatin-related neurotoxicity: How and why? Crit Rev Oncol/ Hematol 2006;59:159-168.

20.Attal N, Bouhassira D, Gautron M, Vaillant JN, Mitry E, Lepere C, et al. Thermal hyperalgesia as a marker of oxaliplatin neurotoxicity: A prospective quantified sensory assessment study. Pain 2009;144:245-52.

http://dx.doi.org/10.1016/j.pain.2009.03.024

21.Grothey A, Nickcevich DA, Sloan JA, Kugler JW, Silberstein PT, Dentchev $\mathrm{T}$, et al. Intravenous calcium and magnesium for oxaliplatin-induced sensory neurotoxicity in adjuvant colon cancer: NCCTG N04C7. J Clin Oncol 2010;29(4):421-7.

http://dx.doi.org/10.1200/JCO.2010.31.5911

22.Argyriou AA, Chroni E, Polychronopoulos P, Iconomou G, Koutras A, Makatsoris T, et al. Efficacy of oxcarbazepine for prophylaxis against cumulative oxaliplatin-induced neuropathy. Neurology 2006;67:2253-5.

http://dx.doi.org/10.1212/01.wnl.0000249344.99671.d4

23.Kono T, Mamiya N, Chisato N, Ebisawa Y, Yamazaki H, Watari J, et al. Efficacy of Goshajinkigan for peripheral neurotoxicity of oxaliplatin in patients with advanced or recurrent colorectal cancer. Hindwai Pub Corp. 2009;2011:1093-110.

24.Binder A, Stengel M, Maag R, Wasner G, Schoch R, Moosig F, et al. Pain in oxaliplatin-induced neuropathy- Sensitization in the peripheral and central nociceptive system. Eur J Cancer 2007;43:2658-63.

http://dx.doi.org/10.1016/j.ejca.2007.07.030

25.Lehky TJ, Leonard GD, Wilson RH, Grem JL, Floeter MK. Oxaliplatin- 
-induced neurotoxicity: Acute hyperexcitability and chronic neuropathy. Muscle Nerve 2004;29:387-92.

http://dx.doi.org/10.1002/mus.10559

26.Park SB, Lin CS, Krishnan AV, Goldstein D, Friedlander ML, Kiernan M. Utilizing natural activity to dissect the pathophysiology of acute oxaliplatin-induced neuropathy. Experimen Neurol 2010;227:120-27.

http://dx.doi.org/10.1016/j.expneurol.2010.10.002

27.Delius S, Eckel F, Wagenpfeil S, Mayr M, Stock K, Kullmann F. Carbamazepine for prevention of oxaliplatin-related neurotoxicity in patients with colorectal cancer: Final results of a randomized, controlled, multicenter phase II study. Invest New Drugs. 2006;25:173-80.

http://dx.doi.org/10.1007/s10637-006-9010-y

28.Nitrini R. Princípios fundamentais. In: Nitrini R, Bacheschi LA. A neurologia que todo médico deve saber. 2a ed. São Paulo: Atheneu; 2003, p.5-54.

29.Kottschade LA, Sloan JA, Mazurczak MA, Johnson DB, Murphy BP, Rowland KM, et al. The use of Vitamin E for the prevention chemotherapy-induced peripheral neuropathy: results of a randomized phase III clinical trial. Supp Care Cancer 2010;10:1018-23.
30. Gramont A, Figer A, Seymour M. Leucovorin and fluorouracil with or without oxaliplatin as first-line treatment in advanced colorectal cancer. J Clin Oncol 2000;18:2938-47.

31.Lecomte T, Landi B, Beaune P, Laurent-Puig P, Loriot MA. Glutahtione S-Transferase P1 polymorphism (Ile $105 \mathrm{Val}$ ) predicts cumulative neuropathy in patients receiving oxaliplatin-based chemotherapy. Clin Cancer Res 2006;12(10):3050-6.

http://dx.doi.org/10.1158/1078-0432.CCR-05-2076

32.Petrioli R, Pascucci A, Francini E, Marsili S, Sciandivasci A, Tassi R, et al. Neurotoxicity of Folfox- 4 as adjuvant treatment for patients with colon and gastric câncer: a randomized study of two different schedules of oxaliplatin. Cancer Chemother Pharmacol 2007;61:105-11.

http://dx.doi.org/10.1007/s00280-007-0454-3

33.Park SB, Goldstein D, Lin CS, Krishnan AV, Friedlander ML, Kiernan MC. Acute abnormalities of sensory nerve functions associated with oxaliplatin- induced neurotoxicity. J Clin Oncol 2009;27(8):1243-9.

http://dx.doi.org/10.1200/JCO.2008.19.3425

34. Tofthagen C, Overcash J, Kip K. Falls in persons with chemotherapy-induced peripheral neuropathy. Supp Care Cancer 2011;11:1127-7. 